\title{
INCLUSÃO DIGITAL E O PROGRAMA PROVÍNCIA DE SÃO PEDRO: A DISTRIBUIÇÃO DOS RECURSOS PÚBLICOS DESTINADOS PARA A EDUCAÇÃO
}

DIGITAL INCLUSION AND THE SÃO PEDRO PROVINCE PROGRAM: THE DISTRIBUTION OF PUBLIC RESOURCES INTENDED FOR EDUCATION

\section{Denise Espich ${ }^{1}$, Fernando do Nascimento Lock², Gabriela Martins Sanfelice ${ }^{3}$}

RECEBIDO EM: 12/10/2018 | ACEITO EM: 02/02/2019

DOI: $10.5902 / 2317175835167$

\section{RESUMO}

O artigo tem como objetivo evidenciar os critérios de distribuição dos recursos financeiros do Estado do Rio Grande do Sul destinados às escolas da rede estadual por meio do Programa de Governo Província de São Pedro executado no período de 2012 a 2014. Trata-se de uma pesquisa documental, baseada em sites governamentais e legislações pertinentes. Os resultados mostram que o Governo do Estado do Rio Grande do Sul, procurou sanar problemas iminentes relacionados a grupos sociais específicos, adotando assim medidas não homogenias às escolas.

Palavras-chave: Programa de governo; Inclusão digital; Educação.

\footnotetext{
1 Possui graduação em Ciências Contábeis pela Universidade Federal de Santa Maria (2016), atualmente é acadêmica do Programa Especial de Graduação de Formacão de Professores para a Educação Profissional (PEG/ UFSM), e mestranda do Programa de Pós-Graduação em Administração da UFSM, atuando principalmente nos seguintes temas: Gestão Pública, Cooperativismo de Crédito e Finanças.

2 Possui graduação em Ciências Contábeis pela Universidade Federal de Santa Maria (1993), Especialização em Contabilidade e Controladoria pela Universidade Federal de Pernambuco (1999), mestrado em Gestão Pública para o Desenvolvimento do Nordeste pela Universidade Federal de Pernambuco (2003) e doutorado em Desenvolvimento Regional pela Universidade de Santa Cruz do Sul (2012). É Professor Adjunto da Universidade Federal de Santa Maria.

3 Graduanda do curso de Ciências Contábeis da Universidade Federal de Santa Maria. Diretora do Departamento de Qualidade e Controle Interno da Caduceu Jr- Consultoria Estratégica em Finanças.
} 
INCLUSÃO DIGITAL E O PROGRAMA PROVÍNCIA DE SÃO PEDRO: A DISTRIBUIÇÃO DOS RECURSOS PÚBLICOS

DESTINADOS PARA A EDUCAÇÃO

\begin{abstract}
The objective of this paper is to show the criteria for the distribution of financial resources of the State of Rio Grande do Sul for the schools of the state network through the Government Program of São Pedro, executed in the period from 2012 to 2014. It is a research documentary, based on governmental websites and relevant legislation. The results show that the Government of the State of Rio Grande do Sul sought to remedy imminent problems related to specific social groups, thus adopting measures not homogenous to schools.
\end{abstract}

Keywords: Government program. Digital inclusion. Education.

\title{
1 Introdução
}

A educação consiste em um dos alicerces de uma sociedade desenvolvida, assim, compreende-se que para o desenvolvimento das atividades educacionais torna-se necessário o dispêndio de recurso financeiro. Deste modo, o artigo investiga o processo de destinação do recurso público do governo do Estado do Rio Grande do Sul para a educação por meio do Programa de Governo Província de São Pedro (PSP), executado no período de 2012 a 2014.

O nome do programa PSP tem origem nas nomenclaturas que ao longo da história foram atribuídos ao atual Estado do Rio Grande do Sul. De acordo com Silva (1968) entre os anos de 1534 até 1889 o Estado foi designado por quarenta e uma nomenclaturas distintas, dentre as quais vinte e duas abrangiam o termo São Pedro em parte do nome. No ano de 1839 a trigésima quinta nomenclatura era Província de São Pedro. Em contraponto a um vínculo histórico com Estado, o programa visou a inclusão digital. Assim, o PSP tem por objetivo "a melhoria da qualidade da educação através da qualificação tecnológica, visando a modernização de equipamentos e de espaços, e principalmente investindo na formação pedagógica dos professores para o uso das mídias no ambiente escolar" (SEDUC/RS, 2014).

A implantação deste programa ocorreu em um Estado que apresenta um histórico de déficit em muitos exercícios e governos em descontinuidade, tanto em relação ao governante quanto ao partido político, ou seja, consistem em formas distintas de compreender as prioridades dos gastos público. Tal cenário resulta em políticas de curto prazo, as quais influenciam na distribuição dos recursos as escolas, e assim definem como estes irão chegar às escolas (por meio de cursos, equipamentos eletrônicos, em dinheiro, etc.), quais escolas irão abranger e a que despesa se destinará a cobrir.

Além disso, em 2017 o Estado ainda passa por um momento histórico de instabilidade financeira e consequentemente contingenciamento dos recursos, o que gera certa desconfiança social para com as contas públicas e 
afirmações precipitadas sem o devido embasamento técnico. De forma que a educação se configura como uma das áreas mais questionadas, por se apresentar como um direito social e o caminho para que no futuro se possam sanar os problemas nas demais áreas de carências sociais. Assim, o artigo busca responder ao seguinte questionamento: quais os critérios estabelecidos, pelo estado do Rio Grande do Sul, para a distribuição dos recursos do programa de governo denominado Província de São Pedro?

O artigo tem como objetivo geral evidenciar os critérios de distribuição dos recursos financeiros do Estado do Rio Grande do Sul destinados às escolas da rede estadual por meio do PSP, para que assim se compreenda se os recursos deste programa chegaram às escolas de maneira uniforme. A relevância social deste consiste na evidenciação do processo de distribuição dos recursos de maneira mais simples e transparente para compreensão de como os recursos saíram dos cofres do Governo do Estado e chegaram até as escolas.

Justifica-se o enfoque no Estado do Rio Grande do Sul, em vista do conturbado momento político que tem se evidenciado pela greve deflagrada pelo CPERS - Centro dos Professores do Estado do Rio Grande Sul na rede estadual de ensino na qual é exigido, entre outras questões, uma solução para o sucateamento das escolas. O Estado é também cenário de protestos que reivindicam, na rede estadual de ensino, reformas e questões estruturais (PORTO, 2016). Hodiernamente, esse contexto demonstra-se ainda mais agravante com as consequências do parcelamento dos salários dos servidores públicos da rede estadual.

Argumenta-se ainda o fato do programa visar à inclusão digital, que consiste em uma crescente necessidade da população em adaptação ao processo de globalização e evolução tecnológica, o que afeta a maneira de ensinar. Deste modo a educação também deve sofrer mudanças e adaptações conforme é evidenciado por Lavinas e Veiga (2013, p. 545).

Aprimorar a escola e seus conteúdos, reduzir os índices de fracasso escolar, reprofissionalizar o professor para modificar a forma de ensinar e de aprender, de modo a que crianças e jovens possam adquirir um novo tipo de conhecimento, dirigido à solução de problemas com criatividade e espírito crítico, são alguns dos argumentos dos que defendem a disseminação das tecnologias de informação e comunicação - TICs - nas escolas para revolucionar o ensino e, assim, renová-lo. Ou, no limite, refunda-lo. (Lavinas e Veiga, 2013, p.545).

Ao tratar dos estudos já existentes acerca da distribuição de recursos públicos, destaca-se a publicação de Parente (2017), relacionado ao Programa Mais Educação (PME), criado por uma ação do Ministério da Educação em 2007 com o objetivo de induzir políticas públicas de ampliação da jornada escolar nas diferentes esferas de governo. A autora propôs-se analisar os impactos do referido programa nas escolas do campo brasileiras, apresentando reflexões sobre limites e possibilidades do PME e da educação em tempo integral. 
INCLUSÃO DIGITAL E O PROGRAMA PROVÍNCIA DE SÃO PEDRO: A DISTRIBUIÇÃO DOS RECURSOS PÚBLICOS DESTINADOS PARA A EDUCAÇÃO

Os principais limites, destacados por ela, decorrem justamente do formato e escopo do PME, pois este demanda ações dos entes federativos, ou seja, contrapartidas para que o Programa seja adequadamente executado, principalmente, no que se refere à ampliação dos espaços físicos da escola e de recursos humanos.

Especificamente acerca do Programa Província de São Pedro (PSP), têmse Morais $(2015$, p.10) que trabalha com a percepção dos professores da rede estadual quanto aos resultados educacionais obtidos por meio da aplicação do PSP, e Bemfica Jr. (2015), o qual aborda o Programa Um Computador por Aluno e Professor (UCA) e o PSP quanto às aplicações e limitações pedagógicas. Porém este artigo é diferenciado, pois aborda o PSP da perspectiva do financiamento, ao analisar como ocorreu a saída do recurso dos cofres do Governo do Estado até os critérios para a aplicação deste recurso público.

Este artigo, está organizado em cinco seções, compostas pela introdução já apresentada, em seguida, a segunda seção trata da revisão da literatura, onde são tratados o financiamento educacional no Rio Grande do Sul e o Programa Província de São Pedro. A terceira seção traz os aspectos metodológicos, na quarta seção são evidenciados resultados e discussões, e na quinta seção são apresentadas as considerações finais.

\section{0 financiamento da educação e o Estado do Rio Grande do Sul}

O acesso à educação, por se tratar de um direito constitucional, consiste em uma despesa que requer, de maneira legal, um percentual mínimo de investimento em relação à arrecadação. As principais fontes de arrecadação dos Estados são as receitas oriundas dos seguintes impostos: Imposto sobre Operações Relativas à Circulação de Mercadorias e sobre Prestação Serviços - ICMS, Imposto sobre Transmissão "Causa Mortis" e Doação - ITCM e, Imposto sobre a Propriedade de Veículos Automotores - IPVA (BRASIL, 1988).

O percentual mínimo, desde o ano de 1988, de obrigação dos Estados é composto por $25 \%$ (vinte e cinco por cento) da receita resultante dos impostos, e os valores provenientes de transferências, em vista que o percentual mencionado foi instituído na Constituição da República Federativa do Brasil 1988 (BRASIL, 1988). É importante que compreenda-se o histórico de financiamento da educação para compreender a atual situação do financiamento da educação, pois a Constituição Federal de 1988 é ainda muito recente para sanar um contexto histórico de legislações inconstantes com relação a estipulação de um mínimo necessário para financiamento da educação. No Quadro 1 é apresentado o histórico de Legislações que estabelecem percentuais mínimos, a nível nacional, para o financiamento da educação nas esferas federal, estadual e municipal. 


\begin{tabular}{|c|c|c|c|c|}
\hline \multirow[b]{2}{*}{ ANO } & \multirow[b]{2}{*}{ DISPOSIÇÃO LEGAL } & \multicolumn{3}{|c|}{ ESFERA DE VINCULAÇÃO } \\
\hline & & UNIÃO & $\begin{array}{l}\text { ESTADOS E DISTRITO } \\
\text { FEDERAL }\end{array}$ & MUNICÍPIOS \\
\hline 1934 & Constituição Federal de 1934 & $10 \%$ & $20 \%$ & $10 \%$ \\
\hline 1937 & Constituicão Federal de 1937 & _- & _. & - \\
\hline 1942 & Decreto Lei 4.958/42 & - & $15 \%$ a $20 \%$ & $10 \%$ a $15 \%$ \\
\hline 1946 & Constituição Federal de 1946 & $10 \%$ & $20 \%$ & $20 \%$ \\
\hline 1961 & Lei Federal 4.024/61 & $12 \%$ & $20 \%$ & $20 \%$ \\
\hline 1967 & Constituição Federal de 1967 & - & - & - \\
\hline 1969 & Emenda Constitucional I & - & - & $20 \%$ \\
\hline 1971 & Lei Federal 5,692/71 & ـ & - & $20 \%$ \\
\hline 1983 & Emenda Constitucional $14 / 83$ & $13 \%$ & $25 \%$ & $25 \%$ \\
\hline 1988 & Constituicão Federal de 1988 & $18 \%$ & $25 \%$ & $25 \%$ \\
\hline
\end{tabular}

Quadro 1: Legislações federais que Estabeleceram Percentuais Mínimos para Financiamento Público da Educação.

Fonte: Oliveira (2007, p. 92).

No Quadro 1 é possível visualizar um contexto histórico inconstante dos percentuais, observa-se que ocorreu a fixação de um percentual mínimo legal para todos os entes federados (União, estados, Distrito Federal e municípios) na Constituição Federal de 1934, de 1946, de 1988, na Lei Federal 4.024/61 e Emenda Constitucional 14/83. Em contrapartida é verificada a inexistência de vinculação mínima da Constituição Federal de 1937 e de 1967 para todos os entes federados. No ano de 1942 a ausência de vinculação para a União apenas, já na Constituição Federal de 1967, Emenda Constitucional I de 1969 e Lei Federal 5.692 não tiveram fixados valores mínimos para financiamento da educação a União, estados e Distrito Federal. É evidenciado nesses períodos, com maior, menor ou nem uma estipulação de percentuais mínimos de destinação de recursos a educação.

Já na constituição do Estado do Rio Grande do Sul, apresenta-se o comprometimento em aplicar um mínimo de 35\% (trinta e cinco por cento) das receitas resultantes dos impostos, que se apresenta superior ao mínimo exigido na constituição federal, "O Estado aplicará, no exercício financeiro, no mínimo, trinta e cinco por cento da receita resultante de impostos, compreendida a proveniente de transferências, na manutenção e desenvolvimento do ensino público". (RIO GRANDE DO SUL, 1989, art. 202).

Apesar de ser mais vantajosa para a educação, a constituição estadual não prevê nem uma sanção normativa para a não realização dos trinta e cinco por cento. Ao considerar as demandas dos demais setores de responsabilidade do Estado, não é correto partir do pressuposto que este percentual efetivamente seja cumprido. Desta forma, compreende-se como percentual mínimo, os vinte e cinco por cento que constam na constituição federal, os quais possuem sanções em seu descumprimento. 
INCLUSÃO DIGITAL E O PROGRAMA PROVÍNCIA DE SÃO PEDRO: A DISTRIBUIÇÃO DOS RECURSOS PÚBLICOS DESTINADOS PARA A EDUCAÇÃO

Os estados, o Distrito Federal e os municípios destinarão, parte dos recursos a serem aplicados na manutenção e desenvolvimento da educação básica e a remuneração dos trabalhadores da educação. Assegurada a distribuição dos recursos mediante a criação, de um Fundo de Manutenção e Desenvolvimento da Educação Básica e de Valorização dos Profissionais da Educação FUNDEB. De modo que se estabeleceu que, uma proporção não inferior a $60 \%$ (sessenta por cento) desses fundos será destinada ao pagamento dos profissionais do magistério da educação básica em efetivo exercício (BRASIL, 2007).

A partir de 2006 foi instituído o FUNDEB, o qual se constitui em um Fundo de natureza contábil, para o qual contribuem a União, os estados, o Distrito Federal e os municípios, de forma que os estados destinam vinte por cento da receita de impostos e transferências com destino à educação (BRASIL, 2007). Este recurso é distribuído para as escolas com base no número de alunos, conforme explica o Ministério da Educação:

Com a Emenda Constitucional n. 53/2006, a sub-vinculação das receitas dos impostos e transferências dos Estados, Distrito Federal e Municípios passaram para $20 \%$ e sua utilização foi ampliada para toda a Educação Básica, por meio do Fundeb, que promove a distribuição dos recursos com base no n. de alunos da educação básica, de acordo com dados do último Censo Escolar, sendo computados os alunos matriculados nos respectivos âmbitos de atuação prioritária (art. 211 da Constituição Federal). Ou seja, os Municípios receberão os recursos do Fundeb com base no número de alunos da educação infantil e do ensino fundamental e os Estados com base nos alunos do ensino fundamental e médio. Da mesma forma, a aplicação desses recursos, pelos gestores estaduais e municipais, deve ser direcionada levando-se em consideração a responsabilidade constitucional que delimita a atuação dos Estados e Municípios em relação à educação básica. (STN, 2014, p. 3).

A porcentagem mencionada de $20 \%$ (vinte por cento) dos recursos de constituição dos fundos, conforme Brasil e STN (2014), foi atingida gradativamente nos seus primeiros 3 (três) anos de vigência. A partir do exercício financeiro de 2010, foram incorporados ao FUNDEB de cada estado e do Distrito Federal. Ainda, a União complementará os recursos de cada FUNDEB, de acordo com Brasil e STN (2014), sempre que, em cada Estado e no Distrito Federal, o valor por aluno não alcançar o mínimo definido nacionalmente.

[...] FUNDEB é hoje a principal fonte financiadora da educação básica pública. No entanto, sua vigência expira no ano de 2020, daí a importancia de se discutir as virtudes e deficiências desse fundo, bem como sua capacidade financeira para o custeio da educação básica, pois somente conhecendo a atual estrutura e mecanismos de funcionamento, poderemos oferecer subsídios para o aprimoramento do referido fundo, bem como para o planejamento daquele que venha a ser seu substituto. (SOUSA, 2016, p. 13). 
Outra fonte de financiamento ocorre por meio da contribuição social do salário-educação conforme redação da Constituição Federal: "A educação básica pública terá como fonte adicional de financiamento a contribuição social do salário-educação, recolhida pelas empresas na forma da lei". (BRASIL, 1988, art. 212, § 5.). De acordo com a Lei Ordinária 9424/1996 em seu art. 15, os recursos oriundos do salário-educação serão beneficiários estudantes do ensino fundamental, que atualmente integra a educação básica.

Deste modo, parte dos percentuais mínimos de investimentos em educação é gerida a nível estadual (5\%), e parte é transferida para o Fundeb e gerida a nível federal (20\%) pelo Fundo Nacional de Desenvolvimento da Educação - FNDE. De forma que este ente gere estes recursos do Fundeb somados aos recursos do Salário Educação. Esta gestão ocorre separadamente para os recursos de cada estado, por meio de programas interligados ao Governo Federal, que repassará os recursos a planos nacionais, que então são direcionados aos estados e municípios ou diretamente as instituições de ensino.

Assim, ao compreender como são geridos os recursos de maneira geral, na esfera estadual, cabe aprofundar a compreensão da gestão dos recursos do Programa Província de São Pedro (PSP), desenvolvido pelo Estado do Rio Grande do Sul, ao verificar como ocorreu sua implantação e alguns de seus resultados.

\section{Programa Província de São Pedro}

O Governo do Estado do Rio Grande do Sul, por meio da Secretaria da Educação (Seduc), em 2014, atendia a cerca de 2.576 escolas, de modo que abrangia um público de aproximadamente 1.200 .000 alunos. E essa Secretaria elaborou o Programa Província de São Pedro (PSP), com o objetivo de desenvolver a qualidade da educação por intermédio da qualificação tecnológica, de forma a visar a modernização de instalações, equipamentos e a capacitação dos professores para trabalharem a utilização de mídias em sala de aula (SEDUC/RS, 2014).

Teve por objetivos específicos, segundo a Seduc/RS (2014), conhecer, aprender, ensinar e dar novo significado as aprendizagens e as relações interpessoais, de maneira que disponibilizou novas ferramentas tecnológicas ao introduzir a escola no universo digital. O programa foi desenvolvido em todas as 30 Coordenadorias Regionais (CRE), e a formação dos professores realizada por meio dos Núcleos de Tecnologia Educacional (NTEs) em parceria com outras instituições.

O PSP organizava o planejamento pedagógico com: um netbook para cada aluno e professor, formação e distribuição de tablets para os professores, uso dos laboratórios móveis com laptops, modernização e ampliação dos laboratórios de informática das escolas, distribuição de lousas eletrônicas e conexão em banda larga. Buscando proporcionar a formação de professores e possibilitar à vivência dos alunos a linguagem tecnológica, apresentou-se 
INCLUSÃO DIGITAL E O PROGRAMA PROVÍNCIA DE SÃO PEDRO: A DISTRIBUIÇÃO DOS RECURSOS PÚBLICOS DESTINADOS PARA A EDUCAÇÃO

como o principal instrumento de modernização tecnológica da rede estadual. Visou, por meio da introdução de computadores no processo de aprendizagem, um parceiro dos professores no trabalho pedagógico (SEDUC/RS, 2014).

Assim, O PSP consistiu em um programa desenvolvido pelo Estado do Rio Grande do Sul por meio da Seduc, em parceria da Secretaria da Fazenda (Sefaz), através da Companhia de Processamento de Dados do Estado do Rio Grande do Sul (Procergs) e da Assessoria de Inclusão Digital do Gabinete do Governador (SEDUC/RS, 2014). Abrange parte dos objetivos do programa RS Mais Digital, o qual foi instituído pelo Decreto 50.800 de 2013, com a finalidade de desenvolver sistemáticas para a inclusão digital, tanto no meio escolar, quanto no meio social também, ou seja, o direito de acesso as tecnologias por parte da população em geral. Conforme consta no seu art. $1^{\circ}$ :

Fica instituído o Programa RS Mais Digital, no âmbito do Gabinete do Governador, por intermédio da Assessoria de Inclusão Digital, com a finalidade de formular e propor diretrizes, objetivos e metas, bem como elaborar políticas públicas e ações no âmbito da inclusão digital, com vista a implementar políticas de conexão à Internet de banda larga que ajudem a democratizar o acesso as novas tecnologias, levando computadores, conexão de internet e cursos de formação às populações mais carentes, integrando a Administração Pública e a sociedade na promoção do exercício da cidadania e na construção do processo de desenvolvimento econômico e social do Estado do Rio Grande do Sul. (RIO GRANDE DO SUL, 2013, art.1).

Quanto aos investimentos ao programa a Seduc (2014) informou já ter investido mais de $\mathrm{R} \$ 100$ milhões até o ano de 2014, na aquisição dos netbooks, instalação de infraestrutura nas escolas e na formação dos professores, que ocorreram através de oficinas, cursos presenciais e à distância, bem como nas próprias escolas.

Assim, encerra-se esta seção de revisão da literatura, descritos os aspectos mais relevantes com relação ao financiamento da educação e ao programa PSP, de forma mais específica. Segue-se então para os aspectos metodológicos deste artigo.

\section{Metodologia}

Do ponto de vista dos procedimentos técnicos trata-se de uma pesquisa documental, pois o artigo vale-se de materiais que ainda não receberam um tratamento analítico (GIL 2008). Especificamente, foram utilizados dados contidos em sites governamentais e legislações.

Quanto à forma de abordagem do problema foi utilizada uma abordagem quantitativa, a qual visa compreender o processo de distribuição dos recursos do Estado ao PSP. 
Conforme Gil (2008, p.28) as pesquisas descritivas apresentam como objetivo essencial à descrição das características de determinada população ou fenômeno ou, seu objetivo pode consistir no estabelecimento de relações entre variáveis. Aplica-se ao artigo, pois este se dispõe a descrever o processo de distribuição dos recursos desde a sua origem no governo estadual até a sua aplicação nas escolas.

A unidade de análise consiste no programa Província de São Pedro, desenvolvido pelo Estado do Rio Grande do Sul, implementado no período de 2012 a 2014, em apoio a programas nacionais como Um computador por Aluno - UCA e Programa Nacional de Tecnologia Educacional - Proinfo. O PSP foi composto pelas modalidades: um por um, criação de NTE, tablets para professores, modernização e ampliação dos laboratórios de informática das escolas, lousas eletrônicas e internet em banda larga. Deste modo, buscou-se evidenciar os critérios específicos de cada modalidade do programa para distribuição dos recursos às escolas da rede estadual.

Para a operacionalização, foram utilizados dados contidos em sites governamentais e legislações, de modo a coletar as informações vinculadas aos critérios de repasse dos recursos. Vale ressaltar que, mesmo fazendo referência ao manual dos demonstrativos fiscais $6^{a}$ edição, para análise do período compreendido foi utilizado o manual vigente na época, ou seja, o manual dos demonstrativos da $5^{\mathrm{a}}$ edição.

A análise ocorreu por meio da análise de conteúdo. Desta forma, abrangeu um conjunto de técnicas de estudo das relações entre os conteúdos e conceitos, com um enfoque, principalmente, nas coocorrências e na estrutura da rede (BARDIN, 2004). Pois, este foco é adequado para a extração de relações de conjuntos de dados.

Com relação aos processos, Bardin (2004) descreve três etapas, sendo elas a pré-análise, a exploração do material, e o tratamento dos resultados, a inferência e a interpretação. Executadas conforme descrito na Tabela 1.

\begin{tabular}{l|l}
\hline Etapas & Procedimentos realizados \\
\hline Pré-análise; & Seleção dos recursos textuais. \\
\hline Exploração do material; & $\begin{array}{l}\text { Leitura dos recursos levantados, sistematizando e relacionando os materiais, verificando as categorias do } \\
\text { programa PSP com seus respectivos critérios de distribuição. }\end{array}$ \\
\hline $\begin{array}{l}\text { Tratamento dos } \\
\text { resultados. }\end{array}$ & $\begin{array}{l}\text { Reuniu-se os dados relevantes por recurso textual, por meio de um resumo individual com informações } \\
\text { dos critérios por modalidade e elaborou-se um esquema para melhor visualizar o processo de distribuição } \\
\text { dos recursos e os critérios aplicados. }\end{array}$ \\
\hline
\end{tabular}

1: Procedimentos da Análise de Conteúdo.

Fonte: Autores. 
INCLUSÃO DIGITAL E O PROGRAMA PROVÍNCIA DE SÃO PEDRO: A DISTRIBUIÇÃO DOS RECURSOS PÚBLICOS DESTINADOS PARA A EDUCAÇÃO

\section{Apresentação e discussão dos resultados}

Identificou-se que os critérios para distribuir os recursos às escolas da rede estadual se aplicam de acordo com a modalidades, que são: Um computador por aluno e professor; Projeto tablet Educacional; Projeto Laboratórios de Informática; modernização e ampliação dos laboratórios de informática das escolas, distribuição de lousas eletrônicas e conexão em banda larga na rede estadual. No Quadro 2, apresenta-se os critérios de acordo com cada modalidade.

\begin{tabular}{|l|l|}
\hline \multicolumn{2}{|l|}{ PROGRAMA PROVÍNCIA DE SÃO PEDRO } \\
\hline MODALIDADE & CRITÉRIOS ESPECÍFICOS \\
\hline UM COMPUTADOR POR ALUNO E PROFESSOR & $\begin{array}{l}\text { Ensino Fundamental de escolas estaduais que fazem fronteira com o } \\
\text { Uruguai. }\end{array}$ \\
\hline PROJETO TABLET EDUCACIONAL & $\begin{array}{l}\text { Rede estadual do Ensino Médio Politécnico, da Educação Profissional e o } \\
\text { Ensino Normal. }\end{array}$ \\
\hline PROJETO LABORATÓRIOS DE INFORMÁTICA & Escolas com mais de 100 alunos do Ensino Médio Politécnico e Normal \\
\hline $\begin{array}{l}\text { MODERNIZAÇÃO E AMPLIAÇÃ DOS LABORATÓRIOS } \\
\text { DE INFORMÁTICA NAS ESCOLAS }\end{array}$ & Sem critério específico. \\
\hline LOUSAS ELETRÔNICAS & Sem critério específico. \\
\hline CONEXÃO EM BANDA LARGA & Sem critério específico. \\
\hline
\end{tabular}

Quadro 2: Critérios específicos para distribuição dos recursos do Programa Província de São Pedro.

Fonte: Autores.

Na modalidade Um Computador por Aluno e Professor: os netbooks foram distribuídos no Ensino Fundamental, das escolas estaduais nos municípios que fazem fronteira com o Uruguai, em algumas escolas localizadas nos Territórios da Paz na região metropolitana e em instituições que já utilizavam esta metodologia em seus projetos (SEDUC/RS, 2014). "A denominação Territórios de Paz, de fato, se estabelece a partir do seu contraditório. Tais territórios são demarcados exatamente pelos altos índices de violência e criminalidade" (LOPES, SCHLEMMER e MOLINA, 2014, p. 153). Por meio destes critérios, esta modalidade do PSP abrangeu à grupos de maior vulnerabilidade social.

O Projeto Tablet Educacional: visou à formação e distribuição de tablets para os professores, de modo que estes professores deveriam atuar rede estadual do Ensino Médio Politécnico, da Educação Profissional e o Ensino Normal (SEDUC/RS, 2014). E conforme informa Seduc/RS (2014), todas as CREs/NTEs já estavam na fase final das formações e entrega dos tablets para professores do Ensino Médio no ano de 2014. Neste mesmo período, por meio de verba federal/estadual, foram liberados 22.000 (vinte e dois mil) tablets para professores da Educação Profissional, em processo de formação ainda em andamento, que aguardava um novo processo de licitação para contemplar a todos os professores. Pois até aquele momento apenas professores regentes de classe e supervisão da escola é que receberam os equipamentos (SEDUC/RS, 2014). 
O Projeto Laboratórios de Informática: visou o planejamento pedagógico com o uso dos Laboratórios Móveis com laptops, de modo que estes, segundo a Seduc/RS (2014), foram entregues às escolas da rede estadual, limitados ao critério de escolas com mais de 100 alunos do Ensino Médio Politécnico e Normal. Cabe ressaltar que todas as $30 \mathrm{CREs} / \mathrm{NTEs}$ realizaram a formação com os professores e utilizaram os Laboratórios de Informática das escolas (SEDUC/RS, 2014). Assim, em cada uma das 30 CREs, apresenta-se um Núcleo de Tecnologia da Educação - NTE. Apesar de existirem em torno de cem assessores em todo o Estado, este é um número insuficiente para dar conta da ampliação do programa (SEDUC/RS, 2014).

Já as modalidades modernização e ampliação dos laboratórios de informática das escolas, distribuição de lousas eletrônicas e conexão em banda larga na rede estadual, não apresentaram seus critérios para aplicação nas escolas da rede estadual de ensino, possivelmente se encaixa em alguma das modalidades anteriormente citadas. O Quadro 3 evidencia este processo de destinação de recursos ao PSP.

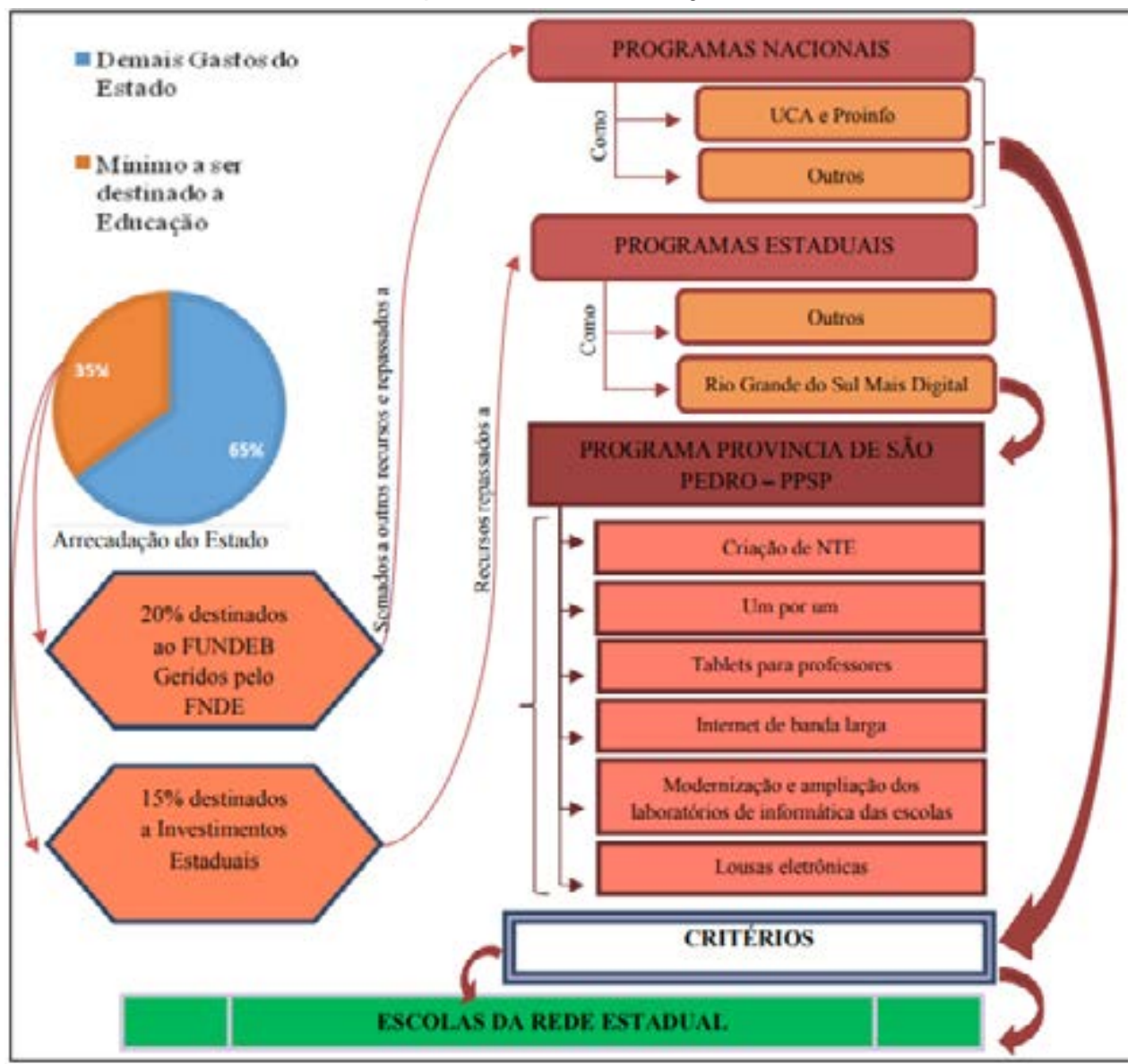

Quadro 3: Processo de destinação de recursos ao Programa Província da São Pedro - PSP.

Fonte: Autores

Observa-se que do montante da arrecadação do Estado que é destinado a educação, 20\% (vinte por cento) é destinado ao FUNDEB e 15\% (quinze por cento) destinados a investimentos do Estado. Ao compreender melhor os recursos do FUNDEB, tem-se que este é somado a outros recursos e gerido 
INCLUSÃO DIGITAL E O PROGRAMA PROVÍNCIA DE SÃO PEDRO: A DISTRIBUIÇÃO DOS RECURSOS PÚBLICOS DESTINADOS PARA A EDUCAÇÃO

pelo FNDE, e destinado a programas nacionais como UCA e Proinfo (entre outros não mencionados neste artigo), de modo que no UCA e Proinfo os seus recursos são repassados por meio de critérios específicos às escolas. Dos $15 \%$ (quinze por cento) de recursos repassados a programas estaduais, parte foi destinada ao programa governamental Província de São Pedro, o qual é composto pelas modalidades: um por um, criação de NTE, tablets para professores, modernização e ampliação dos laboratórios de informática das escolas, lousas eletrônicas e internet em banda larga, os quais seguiram critérios específicos de distribuição dos recursos até chegarem às escolas da rede estadual, desta maneira evidenciam seu complexo processo de distribuição.

De acordo com o site da Secretaria da Educação poucas notícias foram expressas com relação ao montante de recursos distribuídos no período abrangido pelo programa. O Quadro 4 procurou demonstrar a ligação da notícia com a modalidade do programa.

\begin{tabular}{|c|c|c|c|}
\hline \multicolumn{4}{|l|}{ PROGRAMA PROVÍNCIA DE SÃO PEDRO } \\
\hline \multirow{2}{*}{ MODALIDADE } & \multicolumn{3}{|c|}{ Publicações de notícias pela Secretaria de Educação } \\
\hline & 2012 & 2013 & 2014 \\
\hline $\begin{array}{l}\text { gundo a SEDUC/RS } \\
\text { UM COMPUTADOR POR ALUNO E PROFESSOR }\end{array}$ & $(2014)$ & $\begin{array}{l}\text { guarad de teampro } \\
\text { recebe Leptops" }\end{array}$ & ores e 1.134 alunos \\
\hline \multicolumn{4}{|l|}{ PROJETO TABLET EDUCACIONAL } \\
\hline PROJETO LABORATÓRIOS DE INFORMÁTICA & & $\begin{array}{l}\text { "Governo do Estado } \\
\text { contampla escolas } \\
\text { estaduais com } \\
\text { laboratório móvel" }\end{array}$ & \\
\hline $\begin{array}{l}\text { MODERNIZAÇÃO E AMPLIAÇÃ DOS } \\
\text { LABORATÓRIOS DE INFORMÄTICA NAS ESCOLAS }\end{array}$ & & & $\begin{array}{l}\text { "Escolas estaduais do } \\
\text { município de Jaguarão } \\
\text { recebem dois mil } \\
\text { netbooks" }\end{array}$ \\
\hline \multicolumn{4}{|l|}{ LOUSAS ELETRÔNICAS } \\
\hline CONEXÃO EM BANDA LARGA & & & $\begin{array}{l}\text { "Escolas da } 8^{a} \text { CRE } \\
\text { recebem obras de } \\
\text { melhoria para uso da } \\
\text { internet sem fio" }\end{array}$ \\
\hline
\end{tabular}

Quadro 4: Notícias relacionadas ao Programa Província de São Pedro.

Fonte: Autores.

receberam os netbooks que tiveram investimento de $\mathrm{R} \$ 1,3$ milhão."

Conforme explica Castro (2011), a estrutura de financiamento da educação é mista e complexa, com grande volume de recursos oriundos do sistema fiscal e tributário, que é o caso típico dos recursos da vinculação de impostos. $O$ autor comenta ainda que esta vinculação de recursos de impostos para a educação, compreendida como uma reserva de determinado percentual do valor arrecadado, consiste em uma das medidas políticas mais importantes para garantir a disponibilidade de recursos para o cumprimento do vasto rol de responsabilidades do poder público nesta área. Desta forma, a vinculação é importante, entretanto torna mais complexo o percurso percorrido pelos recursos até as instituições de ensino.

Destaca-se ainda, com relação aos serviços e bens educacionais que os cidadãos brasileiros percebem que, de acordo com Castro (2011), estes podem ser 
oferecidos por diversos mecanismos, de modo que estes podem ser tanto públicos quanto privados. Entretanto, quando se situa no âmbito das responsabilidades do poder público, a nível federal, estadual e/ou municipal, utiliza-se de recursos que são essencialmente arrecadados de forma impositiva junto ao cidadão. Assim, além do gasto público, o autor constata que o financiamento e o gasto com educação no país também são efetuados pelas famílias e pelas empresas.

Desta forma, apresentados os resultados e discussões, encerra-se a quarta seção. Para finalizar com a quinta seção, a qual contém as considerações finais.

\section{Considerações Finais}

Por meio deste artigo, pode-se compreender os critérios de distribuição dos recursos financeiros do Estado do Rio Grande do Sul destinados às escolas da rede estadual por meio do Programa de Governo Província de São Pedro executado no período de 2012 a 2014. Verificou-se que os critérios estão vinculados as modalidades do Programa, de forma que na modalidade Um Computador por Aluno e Professor, abrangeu o Ensino Fundamental, das escolas estaduais nos municípios que fazem fronteira com o Uruguai, em algumas escolas localizadas nos Territórios da Paz na região metropolitana e em instituições que já utilizavam esta metodologia em seus projetos.

Já a modalidade denominada Projeto Tablet Educacional, visou professores que atuavam rede estadual do Ensino Médio Politécnico, da Educação Profissional e o Ensino Normal. De maneira distinta, a modalidade denominada Projeto Laboratórios de Informática, visou às escolas da rede estadual, limitados ao critério de escolas com mais de 100 alunos do Ensino Médio Politécnico e Normal. Entretanto as modalidades modernização e ampliação dos laboratórios de informática das escolas, distribuição de lousas eletrônicas e conexão em banda larga na rede estadual, não apresentaram seus critérios para aplicação nas escolas da rede estadual de ensino, possivelmente se encaixa em alguma das modalidades já descritas.

Através da sistemática de distribuição dos recursos, repassados pelo Estado as escolas da rede estadual, verificou-se que por meio do programa denominado Província de São Pedro (PSP), o Estado colaborou com programas nacionais geridos pelo FNDE (o programa UCA e Proinfo), e estas parcerias desenvolvidas que viabilizaram atingir determinadas modalidades do PSP.

O PSP possibilitou a inserção no meio digital tanto a professores quanto a alunos, de forma a auxiliar no processo pedagógico. Observou-se que o governo buscou por meio de algumas modalidades do programa Província de São Pedro medidas para sanar problemas mais eminentes em alguns grupos sociais, com isso os recursos acabaram por não chegar de maneira homogenia a todas as escolas da rede estadual de ensino. Evidenciado na modalidade um por um, tem por critérios o ensino fundamental, às escolas que fazem fronteira com o Uruguai, e algumas escolas localizadas nos Territórios da Paz na região metropolitana e em instituições que já utilizavam esta metodologia em seus projetos. 
INCLUSÃO DIGITAL E O PROGRAMA PROVÍNCIA DE SÃO PEDRO: A DISTRIBUIÇÃO DOS RECURSOS PÚBLICOS DESTINADOS PARA A EDUCAÇÃO

Alguns dos dados levantados apresentam que determinada modalidade ainda não estava concluída até o encerramento do programa em 2014, o que se apresenta como causa para a distribuição dos recursos não ter ocorrido de maneira uniforme a todas as escolas estaduais da rede pública, que neste caso não foi o objetivo da modalidade, mas sim esta apresentou-se inacabada.

Os treinamentos dados aos professores que receberam os tablets podem ter resultado em uma melhor utilização do equipamento. Deste modo presumese que este tenha sido um importante critério na distribuição dos equipamentos. Porém, pode-se questionar se haveria outras prioridades, outros setores, que a escola poderia apresentar carências a serem sanadas. A iniciativa apresenta pelo PSP evidencia aspectos positivos e negativos, deste modo acredita-se que cada uma das instituições apresentara resultados e percepções distintas quanto dos benefícios do programa. Possivelmente se o mesmo programa fosse realizado com outro foco, em outro setor da sociedade, teria um efeito diferente.

Portanto, todos os recursos públicos, ao propiciar as principais condições materiais para viabilizar a formulação e implementação das políticas educacionais, certamente serão relevantes. Entretanto devem ser investidos com planejamento e comprometimento tanto por parte dos que irão receber quanto dos que possibilitam financeiramente os programas. Ao reconhecer que os recursos financeiros são limitados e as necessidades e demandas por bens e serviços educacionais sempre estarão presentes, compreende-se necessário saber priorizar tais necessidades e demandas. Por fim, ao se tratar de impacto oferecido para a população com os referidos programas, é válido destacar a dificuldade de mensuração do retorno. Nota-se que para avaliar de fato a qualidade ou impacto gerado relacionado aos gastos com a eduação é necessário que um ciclo se complete, ou seja, quando completar o ciclo de formação dos alunos. Contudo, é possível apresentar avaliações parciais independentemente do resultado ser satisfatório ou não. Neste sentido, para um estudo futuro, sugere-se averiguar a relação entre o gasto com o PSP e o número de ingressantes no ensino superior.

\section{Referências}

BARDIN, L. Análise de Conteúdo. 70 ed. Lisboa. 2004.

BEMFICA JR, E. S. O Programa Um Computador por Aluno e Professor (UCA) e o Programa Província de São Pedro (PSP): algumas reflexões necessárias. Repositório Digital da Universidade Federal do Rio Grande do Sul. Disponível em: <http://hdl.handle.net/10183/117505>. Acesso em: 22 jul. 2018.

BRASIL. República Federativa do Brasil. Senado Federal. Constituição de 1988. Brasília, DF. Disponível em: <http:// www.planalto.gov.br/ccivil_03/constituicao/ConstituicaoCompilado.htm>. Acesso em: 24 jul. 2018.

BRASIL. Lei n. 11.494, de 20 de junho de 2007. Regulamenta o Fundo de Manutenção e Desenvolvimento da Educação Básica e de Valorização dos Profissionais da Educação - FUNDEB. Diário Oficial da União, Brasília, DF, 22 junho 2007. Disponível em: <http://www.planalto.gov.br/ccivil_03/_ato2007-2010/2007/lei/ |11494.htm>. Acesso em: 14 jul. 2018.

BRASIL; STN - Secretaria do Tesouro Nacional. Manual de Demonstrativos Fiscais: aplicado à União e aos Estados, Distrito Federal e Municípios. 5. ed. Brasília: Secretaria do Tesouro Nacional, Subsecretaria de Contabilidade Pública, Coordenação-Geral de Normas de Contabilidade Aplicadas à Federação. 2014. 688 p. Disponível em: <http://www.tesouro.fazenda.gov.br/documents/10180/471139/CPU_MDF_6_edicao_ 
DENISE ESPICH, FERNANDO DO NASCIMENTO LOCK, GABRIELA MARTINS SANFELICE

versao_24_04_2015.pdf/d066d42d-14c0-454b-9ab8-6386c9f7b0f8>. Acesso em: 30 jul. 2017.

CASTRO, J. A. Financiamento da educação pública no brasil: evolução dos gastos. p. 29-50. IN: GOUVEIA, A. B; PINTO, J. M. R; CORBUCCI, P. R. Federalismo e políticas educacionais na efetivação do direito à educação no Brasil. Brasília: Ipea, 227 p. 2011.

GIL, A. C. Métodos e técnicas de pesquisa social. 6. ed. São Paulo: Atlas. 2008.

LAVINAS, L.; VEIGA, A. Desafios do modelo brasileiro de inclusão digital pela escola. Cadernos de Pesquisa, São Paulo, n. 149 p. 542-569, maio/ago. 2013. Disponível em: <http://www.scielo.br/pdf/cp/v43n149/09.pdf> Acesso em: 22 jun. 2017.

LOPES, D.Q., SCHLEMMER, E., MOLINA, R. K. Atenção Cartográfica em Pesquisas Online sobre Políticas de Inclusão Digital. Revista Polis e Psique, Porto Alegre, n. 3, p. 136-149. 2014. Disponível em:<http://seer.ufrgs.br/ index.php/PolisePsique/article/view/46134>Acesso em: 18 jun. 2017.

MORAIS, C. B. Projeto Província de São Pedro: novas possibilidades tecnológicas para a melhoria da escola pública. Porto Alegre. 2015. Disponível em:<http://www.lume.ufrgs.br/bitstream/ handle/10183/134013/000976487.pdf?sequence=1>. Acesso em: 22 jun. 2017.

OLIVEIRA, R. P. O financiamento da educação. In: OLIVEIRA, R.P.; ADRIÃO, T. Gestão, financiamento e direito à educação: análise da constituição federal e da LDB. 3. ed. São Paulo: Xamã. 2007.

PARENTE, C. M. D. Programa Mais Educação: impactos e perspectivas nas escolas do campo. São Carlos, SP. 2017. Disponível em: <http://www.reveduc.ufscar.br/index.php/reveduc/article/view/1526/606>. Acesso em: 10 mai. 2018.

PORTO, V. Professores decidem iniciar greve na rede pública do RS. Correio do Povo, Porto Alegre. 2016. Disponível em: <http://www.correiodopovo.com.br/Noticias/Ensino\%20/2016/05/587073/Professoresdecidem-iniciar-greve-na-rede-publica-do-RS> Acesso em: 17 jun. 2017.

RIO GRANDE DO SUL. Constituição do Estado do Rio Grande do Sul. Texto constitucional de 3 de outubro de 1989 com as alterações adotadas pelas Emendas Constitucionais de n. 1, de 1991, a 73, de 2017. Lex: Porto Alegre, 3 de outubro de 1989. Disponível em: <http://www2.al.rs.gov.br/dal/LinkClick. aspx?fileticket=liPguzuGBtw\%3d\&tabid=3683\&mid=5358>. Acesso em: 27 jun. 2017.

RIO GRANDE DO SUL. Decreto n. 50.800, de 30 de outubro de 2013. Institui o Programa RS Mais Digital. Publicado no Diário Oficial do Estado do Rio Grande do Sul, n. 211, de 31 de outubro de 2013. Disponível em: <http://www.al.rs.gov.br/filerepository/repLegis/arquivos/DEC\%2050.800.pdf>. Acesso em: 22 jun. de 2017.

SEDUC/RS - Secretaria da Educação do Rio Grande do Sul. Departamento Pedagógico. Programa Província de São Pedro. Porto Alegre. 2014. Disponível em: <http://www.educacao.rs.gov.br/dados/proj_provincia_ apresentacao_2.pdf>. Acesso em: 04 jun. 2018.

SILVA, R. C. Notas à margem da história do Rio Grande do Sul. Porto Alegre: Editora Globo, 255 p. 1968.

SOUSA, A. M. Financiamento da educação básica brasileira: uma análise da utilização dos recursos do FUNDEB no custeio das politicas públicas educacionais. 2017. 83f. Monografia (Especialização em Gestão Pública)- Universidade Estadual da Paraíba, João Pessoa, 2017. Disponível em: <http://dspace. bc.uepb.edu.br/jspui/handle/123456789/13072>. Acesso em: 10 mai. 2018. 